\title{
Effect of Implementing Learning Package of Nesting and Swaddling for Premature Infants on Nurses' Knowledge and Performance in NICU
}

\author{
Gehan EL Nabawy Ahmed*, Boshra Attia Mohammed \\ Lecturers of Pediatric Nursing, Faculty of Nursing, Mansoura University, Egypt \\ *Corresponding author: drgehan_2005@mans.edu.eg
}

Received March 18, 2019; Revised April 22, 2019; Accepted May 13, 2019

\begin{abstract}
Premature infants surviving require advanced medical interventions and professional nursing care. Despite the innovative interventions in the medical field, they remain vulnerable for long-term complications, which is the result of early disruption of their intrauterine life and sudden exposure to an entirely unfamiliar NICU environment. One strategy for helping premature grows normally in NICU is developmental care, which includes positioning, nesting, and swaddling as daily routine care. This study aims to assess the effect of learning package regarding nesting and swaddling for premature on nurses knowledge and performance in NICU. A quasi-experimental research design using one group (pre, immediately post and three months later) was used for this study. Setting: The study was conducted at NICU in Abha Maternity and Child Hospital (AMCH), Abah city, Kingdom of Saudi Arabia. Subjects: 77 nurses who work in the previously mentioned NICU as a convenience sample. Tools: two tools used to collect the study: A Structured questionnaire sheet to assess nurses' knowledge regarding nesting and swaddling and the observation sheet to assess nurses' performance of nesting and swaddling in NICU. Results: There was a statistically significant difference regarding nurses' knowledge and performance about nesting and swaddling immediately after and three months later compared with before learning package. Conclusion: There was a significant positive effect of implementing learning package in improving nurses' knowledge and performance about nesting and swaddling in NICU for premature infants. Recommendations: Neonatal nurses must be provided with the best evidence about applying nesting and swaddling techniques for premature infants as a standard of developmentally supportive care in the NICUs.
\end{abstract}

Keywords: nesting, swaddling, positioning, premature infants, nurse's knowledge, performance, NICU, developmental care

Cite This Article: Gehan EL Nabawy Ahmed, and Boshra Attia Mohammed, "Effect of Implementing Learning Package of Nesting and Swaddling for Premature Infants on Nurses' Knowledge and Performance in NICU.” American Journal of Nursing Research, vol. 7, no. 4 (2019): 428-436. doi: 10.12691/ajnr-7-4-4.

\section{Introduction}

Prematurity is still the major cause of neonatal morbidity and mortality in NICUs worldwide. It is considered the second leading cause of death in neonate after congenital anomalies [1]. Prematurity is a birth occurring before 37 completed weeks of gestation. It comprises nearly 15 million babies each year with a survival chances varying dramatically around the world. Premature babies are high risk for complications that related to anatomic or functional immaturity $[2,3]$. Whereas, the rates of premature birth have been reported to range from $5-7 \%$ of live births in some developed countries and are estimated to be substantially higher in developing countries [4].

Despite the innovative interventions in the medical field to manage complications of premature infant, they remain vulnerable for long-term complications namely; cerebral palsy, mental retardation, developmental delay, school problems, behavioral issues, poor academic achievements, disordered behavioral regulation and overall poor health status. Which are the result of early disruption of their intrauterine life and sudden exposure to entirely unfamiliar NICU environment. Early developmental supportive care which an emerging new field in Neonatology aims to improve neurobehavioral development during this highly vulnerable period of brain growth [5,6].

Developmental care is the nursing and medical interventions to decrease premature infants' stress in NICU. It also results in significantly improved outcomes including decrease the time needed on the ventilator, earlier feeding success, reduce complications, and decrease staying in the hospital. In addition, it improves neurodevelopment during the first 18 months of life [7]. Developmental care aspects include postures support and positioning, through nesting and swaddling, of the infant. It aims to provide optimal physiological, neurological and musculoskeletal development for the preterm neonates [8]. 
Nesting technique is a nursing performance commonly used for premature infant as one of the developmental care. Nesting means the use of rolled-up sheets to form a 'nest' to provide physiological, behavioral and postural stability to the premature infants. Whereas, nesting is one key factor in maintaining a beneficial position for a premature infant through position hands together near face and feet together by using positioning aids to provide a safe snug and supportive nest [9]. Nesting assists change of sleep pattern from erratic disturbed spells to deep peaceful nights and promote comfort and sleep, thus, conserving energy and minimizing weight loss [10].

Swaddling is wrapping an infant tightly with a blanket, pieces of cloth, or bands, to prevent free movement of their limbs. Swaddling is an ancient method used to keep the infants calm through simulating an intra-uterine environment and also improved self-regulation during handling. Certainly, the swaddled positioning provides flexion of the limbs and trunk and facilitates of midline skills. Also, it assists neonate's self-regulation and maximizes neonate's stability, preserves energy, growth, and promotes neurobehavioral organization [11].

Nesting and swaddling as components of developmental care used to improve infant's sleep quality and decrease crying. Additionally, enhance heart rate, respiratory rate and oxygen saturation. Premature infants who receive developmental positioning through applying nesting technique by placing simple sheet rolls to provide supports and boundaries, they can feel something protective around them and stay in the hospital for less time in addition gain weight better [12,13]. Therefore many recent studies recommended that the importance of applying nesting technique for neonates in the NICUs as standard of developmentally supportive positioning care and provide a training program for neonatal nurses regarding the application of nesting and swaddling techniques for premature infants [9,14-20].

\subsection{Significance of the Study}

Nurses comprise the greatest portion of the health-care system and they are responsible for the quality of care provided to everyone along his lifespan. Potter et. al, [21] as cited in Nasr \&Hassan [22] stated that educating the clients is a role for nurses in all health care settings; the nurse is often the main source of information about health promotion that is why they have a very important role in the educational program $[23,24]$. Since pediatric nurses are the key members of the health team in NICU and play an important role to improve quality of care in NICU, therefore, neonatal intensive care nurse should be equipped with the recent evidence in newborn care and should be alert to provide developmental care in an NICU setting. Although nesting and swaddling have been subject to several reviews from the perspective of infant outcomes, there is comparatively little evidence of its impact on neonatal staff. Moreover, most of the nurses in the NIC are eager to learn about nesting and swaddling for premature. So, this study seeks to redress this issue and the findings of this study will add to the body of knowledge to use developmentally supportive positioning techniques in premature infants to facilitate their growth and development. Therefore, the current study aimed to assess the effect of the learning package regarding nesting and swaddling for premature infants on nurses knowledge and performance in NICU.

\subsection{Aim of the Study}

The aim of this study was to assess the effect of learning package about nesting and swaddling for premature infants on nurses knowledge and performance in NICU. This aim can be achieved through:-

1. Assessment of nurses' knowledge and performance about nesting and swaddling for premature in NICU.

2. Developing and implementing a learning package on nurses' knowledge and performance about nesting and swaddling for premature in NICU.

3. Evaluating the effect of implementing a learning package on nurses' knowledge and performance about nesting and swaddling for premature in NICU.

\subsection{Operational Definitions}

Effect means a change produced by an action or cause, a result or an outcome. In this study, it refers to the extent to which learning package has achieved the desired effect on nurse' knowledge and performance about nesting and swaddling for premature in NICU.

Learning Package is a written material developed to teach a concept or skill, combined of multi-media. It consisted of related course objectives, content, learning experiences. In this study it refers to a booklet containing general and specific objectives, content (theoretical and practical) and various teaching methods and audiovisual materials.

Nesting means to create and settle into a warm and secure refuge (American Heritage Dictionary). In this study, it refers to the application of comfortable and secure boundary or an enclosure using a rolled blanket/towels or cot sheets around the immediate physical environment of the neonate.

Swaddling means wrapping an infant tightly with a blanket, pieces of cloth, or bands, to prevent free movement of their limbs.

\subsection{Research Hypotheses}

Implementing a learning package about nesting and swaddling for premature infants will improve nurses' knowledge and performance in NICU.

\subsection{Research Design}

A quasi-experimental research design using one group (pre, immediately post and three months later) was used for this study.

\subsection{Setting}

The study was conducted at Neonatal Intensive Care Unit (NICU) in Abha Maternity and Child Hospital (AMCH), Abah city, Kingdom of Saudi Arabia. This unit is internally classified into18 rooms which divided to three separate parts according to the severity of the 
admitted neonate into ordinary unit, intermediate care unit, and intensive care unit. It includes 51 incubators and the total number of the nursing staff was 85 nurses.

\subsection{Subjects}

A convenience sample composed of 77 nurses who are responsible for providing care for premature infants in the previously mentioned setting regardless their age, qualifications or years of experience and not attending other educational activities related to nesting and swaddling.

\section{Tools of Data Collection}

Data were collected by using two tools (a structured questionnaire sheet \& observational checklist sheet) which were developed by the researchers after reviewing related literature and previous studies relevant to the problem $[9,25,26]$.

Tool 1: A Structured Questionnaire Sheet aims to assess nurses' knowledge regarding nesting and swaddling. It includes three parts:-

Part I: Characteristics of studied nurses including their age, educational level, experience years in NICU and if they attended any training program regarding nesting and swaddling.

Part II: It includes questions were in the form of multiple choice questions to assess nurses' knowledge regarding nesting and swaddling.

Part III: This part assesses the obstacles for performing nesting and swaddling for premature in NICU as reported by nurses.

Tool 2: Observational checklist sheet:

It was used to assess the actual nurses' performance regarding nesting and swaddling for premature infants in NICU.

\subsection{Scoring System}

The scoring of the nurses' answers structured questionnaire sheet to assess their level of knowledge was considered as poor if the percent score was $(<60 \%)$, average if the percent score was (60\%- $<75 \%)$ and good if the percent score was $(\geq 75 \%)$. As regards to their performance regarding nesting and swaddling for premature infants in NICU was considered as competent if the percent score was $(\geq 85 \%)$ and incompetent if $(<85 \%)$.

\subsection{Data Collection Procedure}

\subsubsection{Ethical Considerations}

Prior to data collection, approval was obtained from the authorized directors the hospitals' administrative authorities of Abha Maternity and Child Hospital (AMCH) and Also the permission obtained from the head nurse of the NICU after the researcher explains the aims, process and expected outcomes of the study. Informed consent was obtained from the nurses after complete description of the study's aim and the process by the researcher to obtain their acceptance for participation. Nurses were informed that their participation is voluntary and they have the right to withdraw from the study at any time without giving any reason and without any effect on their work. They were assured that all information collected would be kept confidential and these were to be used only for the research purpose. The rights, privacy and safety of the study sample were secured

\subsubsection{Validity and Reliability}

The tools for data collection were reviewed by a panel of five experts in the field of pediatric nursing and neonatal medicine to test its content validity. Minor modification was done on the tools. Tools reliability was done using Alpha Cronbach's coefficient test, the alpha reliability of tool 1 was $(\alpha=0.83)$, while, reliability of tool 2 was $(\alpha=0.90)$.

\subsubsection{Pilot Study}

A pilot study was conducted on $10 \%$ of the study sample size in order to test the clarity, feasibility, viability and applicability of the tools, as well as to assess the time required to fulfill the tools and modifications were done accordingly.

Data collection process was done over a period of 6 months started from the beginning of November 2017 to the end of April 2018.

\subsection{Intervention: Done Through Three Phases}

\section{a. Assessment phase:}

This phase was started by interviewing the nurses at NICU. The researcher started by introducing herself to nurses and explains the aim of the study, process and the nurse's roles during the participation of the study. Then every nurse was subjected to the following:

Assessing their knowledge about nesting and swaddling. Responses to items of the interviewing questionnaire were filled by the researchers where every nurse was interviewed from 1-2 times for 20-30 minutes in each session in the morning depending upon her physical and mental readiness. Using (Tool 1- Part II)

Assessing the obstacles for performing nesting and swaddling for premature infants in NICU as reported by nurses. Using (Tool 1- Part III).

Observing the actual nurses' performance about nesting and swaddling for premature infants in NICU. Using (Tool 2). The observation of nurse's performance was done during the morning and afternoon shift.

\section{b. Implementation phase:}

The researchers designed the learning package based on the actual assessment of the nurses needs to achieve the following objectives: improve nurses' knowledge and performance regarding nesting and swaddling for preterm in NICU.

The contents of the learning package were given over 4 sessions, divided into two theoretical sessions and two practical.

According to the morning and afternoon shift's work schedule of the study nurses, the researcher divided them into small groups. Each group containing 6-8 nurses to facilitate group discussion. 
The first two sessions covered all theoretical content emphasized on the definition of nesting and swaddling, the benefits of it, methods to overcome obstacles for performing nesting by using available resources and supplies in the NICU.

- The next two sessions concerned with the demonstration of accurate and correct technique of swaddling in addition to different techniques of nesting (prone, supine or side lying).

- The researchers demonstrated all clinical aspects of nesting and swaddling supportive care to every nurse individually. The researchers summarized each session and give feedback for the nurses at the end of it.

- Nurses' performance was evaluated immediately after implementation and three months later using Tool 2. The assessment of each nurse's performance took 25-35 minutes.

- Various teaching methods and audiovisual materials were used during the learning package such as lectures, group discussion, demonstration and redemonstration, poster, video film and power point presentation, as well as booklet were used as teaching media.

\section{c. Evaluation phase:}

The learning package was evaluated immediately and three months after the implementation using (Tool 1 - part II and Tool 2).

\section{Statistical Analysis}

Statistical Package for the Social Sciences (SPSS) for version 19.0 was used for data analysis. The data were revised, coded, tabulated, and presented using descriptive statistics in the form of frequencies and percentage for qualitative variables, and means and standard deviations for quantitative variables. The following statistical measures were used: Chi square and repeated measure ANOVA tests were used for test of significance. The results were accepted to be statistically significant for $\mathrm{p}<0.05$.

\section{Results}

Table 1 revealed that the mean age of studied nurses was $28.9 \pm 3.3$. Regarding nurses' level of education, most of the nurses (93.5\%) had a bachelor degree in nursing science while only $6 \%$ had a diploma in nursing. Near half of the nurses (48.1\%) having from 5 to less than 10 years of experience. While, less than one third (27.3\%) of them having less than 5 years of experience with mean years of experience $7.5 \pm 2.5$. As regards nurses' attainment of previous training courses, $83.1 \%$ did not attend any program or courses regarding nesting and swaddling for premature infants.

Table 2 illustrated that there were statistically significant differences regarding nurses' knowledge about nesting and swaddling through phases of the learning package.

Table 1. Percentage Distribution of Nurses according to their Characteristics

\begin{tabular}{|c|c|c|}
\hline \multicolumn{3}{|l|}{ No. $=77$} \\
\hline Characteristics of nurses & Frequency & $\%$ \\
\hline \multicolumn{3}{|l|}{ Age in years } \\
\hline - $20-<25 \mathrm{Y}$ & 15 & 19.5 \\
\hline $25-<30 Y$ & 36 & 46.7 \\
\hline - $30-<35 \mathrm{Y}$ & 19 & 24.7 \\
\hline - $35+\mathrm{Y}$ & 7 & 9.1 \\
\hline $\mathrm{X} \pm \mathrm{SD}$ & \multicolumn{2}{|c|}{$28.9 \pm 3.3$} \\
\hline \multicolumn{3}{|l|}{ Level of education: } \\
\hline - Bachelor of nursing & 72 & 93.5 \\
\hline • Nursing Diploma & 5 & 6.5 \\
\hline $\begin{array}{l}\text { Years of experience in the NICU: } \\
\bullet<5 \mathrm{Y}\end{array}$ & 21 & 27.3 \\
\hline - $5-<10 \mathrm{Y}$ & 37 & 48.1 \\
\hline - $10-<15 \mathrm{Y}$ & 17 & 22.1 \\
\hline - $15+\mathrm{Y}$ & 2 & 2.5 \\
\hline $\mathrm{X} \pm \mathrm{SD}$ & \multicolumn{2}{|c|}{$7.5 \pm 2.5$} \\
\hline $\begin{array}{l}\text { Attendance of training courses about nesting } \\
\text { and swaddling for premature babies: } \\
\text { - yes }\end{array}$ & 13 & 16.9 \\
\hline - No & 64 & 83.1 \\
\hline
\end{tabular}

Table 2. Nurses' Knowledge about Nesting and Swaddling through Phases of Learning Package (n=77)

\begin{tabular}{|c|c|c|c|c|c|c|c|}
\hline \multirow{2}{*}{ Items } & \multicolumn{2}{|c|}{ Before learning package } & \multicolumn{2}{|c|}{ Immediately after learning package } & \multicolumn{2}{|c|}{3 months after learning package } & \multirow{2}{*}{ P-value } \\
\hline & No & $\%$ & No & $\%$ & No & $\%$ & \\
\hline \multicolumn{7}{|c|}{ Definition / meaning of nesting and swaddling: } & \multirow{4}{*}{$<0.001 * *$} \\
\hline Poor & 64 & 83.1 & 7 & 9.1 & 9 & 11.7 & \\
\hline Average & 7 & 9.1 & 11 & 14.3 & 13 & 16.9 & \\
\hline Good & 6 & 7.8 & 59 & 76.6 & 55 & 71.4 & \\
\hline \multicolumn{7}{|c|}{ Basis for performing nesting and swaddling for premature: } & \multirow{4}{*}{$<0.001 * *$} \\
\hline Poor & 72 & 93.5 & 11 & 14.3 & 13 & 16.9 & \\
\hline Average & 2 & 2.6 & 13 & 16.9 & 9 & 11.7 & \\
\hline Good & 3 & 3.9 & 53 & 68.8 & 55 & 71.4 & \\
\hline \multicolumn{7}{|c|}{ Similarity between nesting and swaddling with other supportive procedures : } & \multirow{4}{*}{$<0.001^{* *}$} \\
\hline Poor & 74 & 96.1 & 6 & 7.8 & 7 & 9.1 & \\
\hline Average & 2 & 2.6 & 10 & 13.0 & 10 & 13.0 & \\
\hline Good & 1 & 1.3 & 61 & 79.2 & 60 & 77.9 & \\
\hline \multicolumn{7}{|c|}{ Benefits of nesting and swaddling for premature: } & \multirow{4}{*}{$<0.001^{* *}$} \\
\hline Poor & 69 & 89.6 & 4 & 5.2 & 7 & 9.1 & \\
\hline Average & 5 & 6.5 & 9 & 11.7 & 16 & 20.8 & \\
\hline Good & 3 & 3.9 & 64 & 83.1 & 54 & 70.1 & \\
\hline
\end{tabular}

Chi square test for comparing between before, immediately, and 3 months after the learning package

* Statistically significant at $\mathrm{p} \leq 0.05$. 


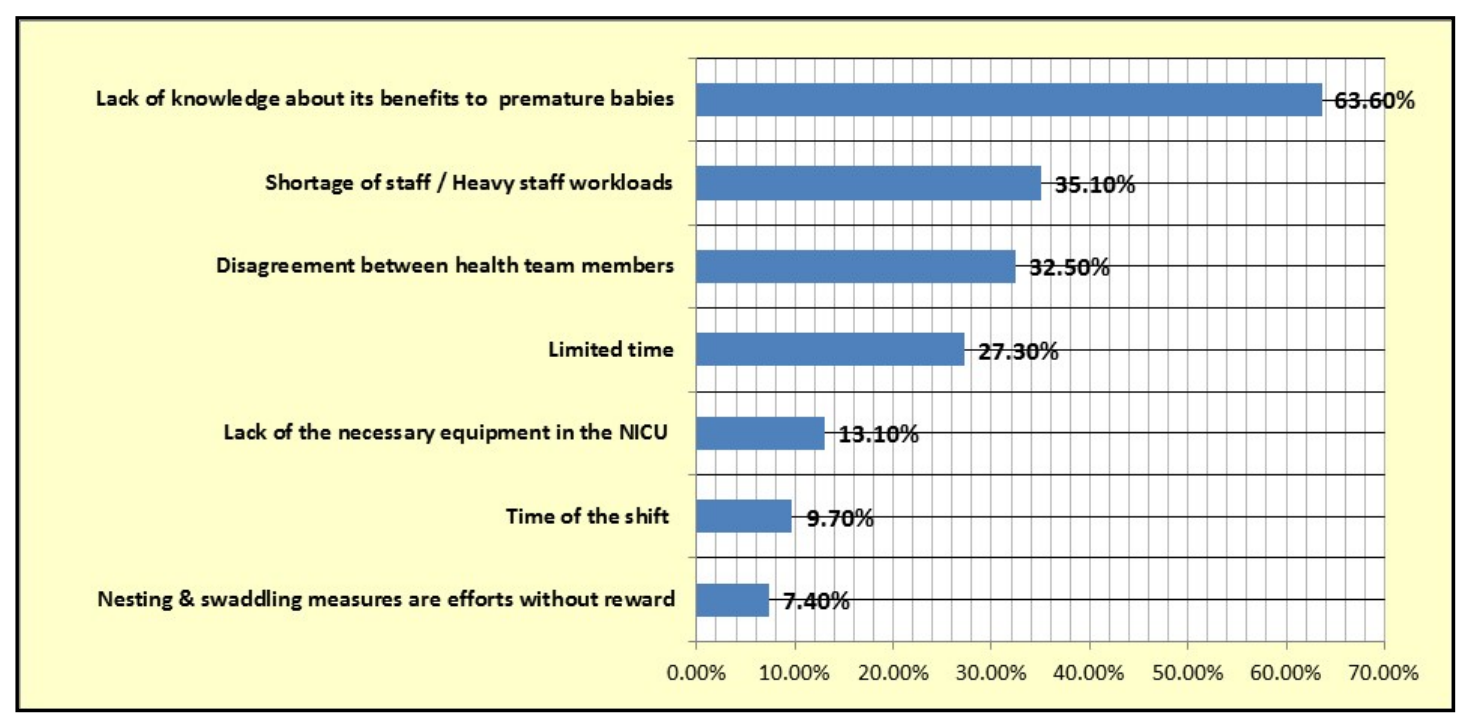

Figure 1. Percentage of obstacles for performing Nesting and Swaddling for premature infant as reported by NIC nurses

In relation to the meaning of nesting and swaddling, there was only $7.8 \%$ of them have good before the application of learning package compared to $76.6 \%$ and $71.4 \%$ immediately and 3 months after learning package application $(p=<0.001)$. As regard level of nurses' knowledge related to the basis for performing nesting and swaddling to premature was only $1.3 \%$ of them have good before the application of learning package compared to $68.8 \%$ and 71.4 immediately and 3 months after learning package application $(\mathrm{p}=<0.001)$. Concerning the similarity between nesting and swaddling other supportive procedures, this table indicated that $3.9 \%$ of nurses had good level before the application of learning package compared to $79.2 \%$ and $77.9 \%$ immediately and 3 months after learning package application ( $\mathrm{p}=<0.001$ ). Regarding the benefits of nesting and swaddling for premature infants, the result revealed that $3.9 \%$ of them have good level before the application of learning package while $83.1 \%$ and $70.1 \%$ have good level immediately and 3 months after learning package application $(\mathrm{p}=<0.001)$.

Concerning the obstacles for performing nesting and swaddling for premature as reported by nurses, this figure illustrated that about two-thirds of nurses (63.6\%) stated that lack of knowledge about its benefits to the premature infants as an obstacle for applying nesting and swaddling. Moreover, 35.1\% of them mentioned that the shortage of staff and heavy workloads are the obstacle of nesting and swaddling care for premature infants. While the minority (7.4\%) of them reported that nesting and swaddling measures are efforts without reward.

Table 3. Nurses' Performance of Nesting for Premature through Phases of Learning Package (n=77)

\begin{tabular}{|c|c|c|c|c|c|c|c|c|c|c|c|c|c|}
\hline \multirow{3}{*}{ Items } & \multicolumn{4}{|c|}{ Before learning package } & \multicolumn{4}{|c|}{$\begin{array}{l}\text { Immediately after } \\
\text { learning package }\end{array}$} & \multicolumn{4}{|c|}{$\begin{array}{c}\text { months after learning } \\
\text { package }\end{array}$} & \multirow{3}{*}{$\mathbf{P}$} \\
\hline & \multicolumn{2}{|c|}{ Done } & \multicolumn{2}{|c|}{ Not done } & \multicolumn{2}{|c|}{ Done } & \multicolumn{2}{|c|}{ Not done } & \multicolumn{2}{|c|}{ Done } & \multicolumn{2}{|c|}{ Not done } & \\
\hline & No & $\%$ & No & $\%$ & No & $\%$ & No & $\%$ & No & $\%$ & No & $\%$ & \\
\hline \multicolumn{14}{|l|}{ Nesting procedure -Prone } \\
\hline $\begin{array}{l}\text { Prepare the equipment (Appropriate Size } \\
\text { Bunting, Cloth diapers and/or T-shirts, } \\
\text { Boundary rolls) }\end{array}$ & 3 & 3.9 & 74 & 96.1 & 68 & 88.3 & 9 & 11.7 & 67 & 87.0 & 10 & 13.0 & $<0.001^{* *}$ \\
\hline $\begin{array}{l}\text { Make an appropriate size linen support for } \\
\text { the baby’s trunk }\end{array}$ & 5 & 6.5 & 72 & 93.5 & 75 & 97.4 & 2 & 2.6 & 73 & 94.8 & 4 & 5.2 & $<0.001^{* *}$ \\
\hline $\begin{array}{l}\text { Place the linen support in the middle third of } \\
\text { the bunting vertically }\end{array}$ & 2 & 2.6 & 75 & 97.4 & 67 & 87.0 & 10 & 13.0 & 65 & 84.4 & 12 & 15.6 & $0.02 *$ \\
\hline $\begin{array}{l}\text { Place the baby deep into the "pocket" of the } \\
\text { bunting }\end{array}$ & 4 & 5.2 & 73 & 94.8 & 68 & 88.3 & 9 & 11.7 & 69 & 89.6 & 8 & 10.4 & $<0.001^{* *}$ \\
\hline $\begin{array}{l}\text { Allow the shoulders to fall forward and the } \\
\text { arms to "hang" somewhat }\end{array}$ & 6 & 7.8 & 71 & 92.2 & 69 & 89.6 & 8 & 10.4 & 67 & 87.0 & 10 & 13.0 & $<0.001^{* *}$ \\
\hline $\begin{array}{l}\text { Place straps and use boundaries inside or } \\
\text { outside the bunting }\end{array}$ & 1 & 1.3 & 76 & 98.7 & 64 & 83.1 & 13 & 16.9 & 61 & 79.2 & 16 & 20.8 & $0.03^{*}$ \\
\hline \multicolumn{14}{|l|}{ Nesting procedure -Supine or Side Lying } \\
\hline $\begin{array}{l}\text { Prepare the equipment (Appropriate size } \\
\text { bunting Cloth diapers and/or t-shirts to make } \\
\text { supports for the shoulders, Boundary } \\
\text { rolls/bumper }\end{array}$ & 3 & 3.9 & 74 & 96.1 & 68 & 88.3 & 9 & 11.7 & 67 & 87.0 & 10 & 13.0 & $<0.001 * *$ \\
\hline $\begin{array}{l}\text { Position baby deep in the bunting pocket } \\
\text { with the hips and knees flexed }\end{array}$ & 4 & 5.2 & 73 & 94.8 & 68 & 88.3 & 9 & 11.7 & 69 & 89.6 & 8 & 10.4 & $<0.001^{* *}$ \\
\hline $\begin{array}{l}\text { Position the linen rolls to provide support } \\
\text { behind the shoulders }\end{array}$ & 6 & 7.8 & 71 & 92.2 & 69 & 89.6 & 8 & 10.4 & 67 & 87.0 & 10 & 13.0 & $<0.001^{* *}$ \\
\hline $\begin{array}{l}\text { Strap the baby in and use boundary } \\
\text { rolls/bumpers as needed }\end{array}$ & 2 & 2.6 & 75 & 97.4 & 67 & 87.0 & 10 & 13.0 & 65 & 84.4 & 12 & 15.6 & $0.02 *$ \\
\hline
\end{tabular}

Chi square test for comparing between before, immediately, and 3 months after the learning package

*: Statistically significant at $\mathrm{p} \leq 0.05$. 
Table 3 clarifies that there was a highly statistically significant difference between nurses' performance of nesting for premature infants before, immediately and 3 months after application of learning package as revealed by $(\mathrm{P}<0.001)$. This means that there is improvement in nurses' performance regarding nesting, either making a nest prone or a nest supine or side lying, post application of learning package compared with pre-learning package.

Table 4. Nurses' Performance of Swaddling for Premature through Phases of Learning Package (n=77)

\begin{tabular}{|c|c|c|c|c|c|c|c|c|c|c|c|c|c|}
\hline \multirow{3}{*}{ Items } & \multicolumn{4}{|c|}{ Before learning package } & \multicolumn{4}{|c|}{$\begin{array}{c}\begin{array}{c}\text { Immediately learning } \\
\text { package }\end{array} \\
\end{array}$} & \multicolumn{4}{|c|}{$\begin{array}{c}\text { months after learning } \\
\text { package }\end{array}$} & \multirow{3}{*}{$\mathbf{P}$} \\
\hline & \multicolumn{2}{|c|}{ Done } & \multicolumn{2}{|c|}{ Not done } & \multicolumn{2}{|c|}{ Done } & \multicolumn{2}{|c|}{ Not done } & \multicolumn{2}{|c|}{ Done } & \multicolumn{2}{|c|}{ Not done } & \\
\hline & No & $\%$ & No & $\%$ & No & $\%$ & No & $\%$ & No & $\%$ & No & $\%$ & \\
\hline $\begin{array}{l}\text { To swaddle, spread the blanket out flat, with } \\
\text { one corner folded down. }\end{array}$ & 10 & 13.0 & 67 & 87.0 & 71 & 92.2 & 6 & 7.8 & 72 & 93.5 & 5 & 6.5 & $<0.001^{* *}$ \\
\hline $\begin{array}{l}\text { Lay the baby face-up on the blanket, with her } \\
\text { head above the folded corner. }\end{array}$ & 11 & 14.3 & 66 & 85.7 & 72 & 93.5 & 5 & 6.5 & 73 & 94.8 & 4 & 5.2 & $<0.001^{* *}$ \\
\hline $\begin{array}{l}\text { Straighten her left arm, and wrap the left } \\
\text { corner of the blanket over her body and tuck } \\
\text { it between her right arm and the right side of } \\
\text { her body. }\end{array}$ & 4 & 5.2 & 73 & 94.8 & 68 & 88.3 & 9 & 11.7 & 69 & 89.6 & 8 & 10.4 & $<0.001^{* *}$ \\
\hline $\begin{array}{l}\text { Then tuck the right arm down, and fold the } \\
\text { right corner of the blanket over her body and } \\
\text { under her left side. }\end{array}$ & 3 & 3.9 & 74 & 96.1 & 68 & 88.3 & 9 & 11.7 & 67 & 87.0 & 10 & 13.0 & $<0.001^{* *}$ \\
\hline $\begin{array}{l}\text { Fold or twist the bottom of the blanket } \\
\text { loosely and tuck it under one side of the } \\
\text { baby. }\end{array}$ & 5 & 6.5 & 72 & 93.5 & 75 & 97.4 & 2 & 2.6 & 73 & 94.8 & 4 & 5.2 & $<0.001^{* *}$ \\
\hline $\begin{array}{l}\text { Make sure her hips can move and that the } \\
\text { blanket is not too tight. "You want to be able } \\
\text { to get at least two or three fingers between } \\
\text { the baby's chest and the swaddle". }\end{array}$ & 7 & 9.1 & 70 & 90.9 & 76 & 98.7 & 1 & 1.3 & 69 & 89.6 & 8 & 10.4 & $<0.001^{* *}$ \\
\hline
\end{tabular}

Chi square test for comparing between before, immediately, and 3 months after the learning package

*Statistically significant at $\mathrm{p} \leq 0.05$.

Table 5. Distribution of Nurses According to their Total Percent Scores of Knowledge and Performance of Nesting and Swaddling for Premature through Phases of Learning Package $(n=77)$

\begin{tabular}{|c|c|c|c|c|c|c|c|}
\hline \multirow[t]{2}{*}{ Items } & \multicolumn{2}{|c|}{$\begin{array}{c}\text { Before learning } \\
\text { package }\end{array}$} & \multicolumn{2}{|c|}{$\begin{array}{c}\text { Immediately after } \\
\text { learning package }\end{array}$} & \multicolumn{2}{|c|}{$\begin{array}{c}3 \text { months after learning } \\
\text { package }\end{array}$} & \multirow[t]{2}{*}{$\mathbf{P}$} \\
\hline & No & $\%$ & No & $\%$ & No & $\%$ & \\
\hline \multicolumn{7}{|c|}{ Total Percent Scores of Knowledge } & \multirow{4}{*}{$<0.001^{* *}$} \\
\hline - Poor & 69 & 89.6 & 7 & 9.1 & 9 & 11.7 & \\
\hline - Average & 5 & 6.5 & 11 & 14.3 & 12 & 15.6 & \\
\hline - Good & 3 & 3.9 & 59 & 76.6 & 56 & 72.7 & \\
\hline \multicolumn{7}{|c|}{ Total Percent Scores of Performance } & \multirow[b]{3}{*}{$<0.001^{* *}$} \\
\hline - Incompetent & 72 & 93.5 & 7 & 9.1 & 9 & 11.7 & \\
\hline - Competent & 5 & 6.5 & 70 & 90.9 & 68 & 88.3 & \\
\hline
\end{tabular}

ANOVA test with repeated measures for comparing between different period *Statistically significant at $\mathrm{p} \leq 0.05$.

Table 4 illustrates that there was a highly statistically significant difference between nurses' performance of swaddling for premature before, immediately and 3 months after application of learning package as revealed by $(\mathrm{P}<0.001)$. This means that there is an improvement in nurses' performance regarding swaddling post application of learning package compared with pre-learning package.

The data presented in Table 5 shows the most of the nurses (89.6\%) had poor knowledge before learning package, while the majority (76.6\%, and $72.7 \%$ ) of them had good knowledge, immediately, and 3 months after application of learning package respectively with a very high statistical significant difference ( $p<0.001)$. In addition this table reveals the most of the nurses (93.5\%) were incompetent in their performance before learning package while the majority (90.9\%, and $88.3 \%)$ of them were improved to be competent immediately and 3 months after application of learning package with a very high statistically significant difference $(\mathrm{p}<0.001)$.

\section{Discussion}

Premature infants face many challenges in different areas of development especially during staying in NICU, because they born early with immature neurological functioning [10]. One strategy for reducing the irritating effects of these challenges and helping premature grow normally in NICU is developmental care which is becoming worldwide standard care and is an important part of nursing care. Nesting and swaddling is an important aspect of developmental care [27]. Therefore, the aim of this study was to assess the effect of the learning package regarding nesting and swaddling for premature on nurses knowledge and performance in NICU.

Regarding studied nurses' socio-demographic characteristics, the present study results illustrated that the studied nurses mean age was $28.9 \pm 3.3$ and most of them (93.5\%) had a bachelor degree in nursing science. About $48.1 \%$ of them had five to less than ten years of experience with mean years of experience was $7.5 \pm 2.5$. These results are not 
similar to other studies as illustrated in the following; Mohammed et al, [28] who conduct a study to "investigate the effect of preterm neonates' developmental supportive care program on nurses' performance" and found that, the mean age of nurses was $37.52 \pm 8.01$ and more than two-thirds of them (72\%) had Technical Nursing School certificate, while (40\%) of the nurses had 15 to less than 20 years of experience. Additionally, Abd El- Aziz, et al [29] who "design and implement an educational program to improving nurses' performance towards non-pharmacological pain management among neonates in neonatal intensive care unit" found that more than two fifths of the studied nurse's age was between 30 years old or more with mean age of $30.6 \pm 2.7$, and more than twofifths of them had equal to or more than 10 years of experience working as a neonatal nurse. Furthermore, Costa et al, [30] who found that the age of the neonatal nurses varied from 21 to 52 years with an average of 30.8 years. This may explain the relationship between knowledge of the participant nurses and their experiences. This is not in line with Hassan and Nasr [31] whose results revealed that the years of experience hadn't an influence on their knowledge.

In relation to the level of education, most of the studied nurses (93.5\%) had a bachelor degree in nursing science. This finding agreed with Abd El- Aziz et al, [29] who found that more than half of the nurses had a bachelor degree in nursing science. Moreover, it is also with the same line with Mehrnoush, et al [32], they found that the majority of the participating nurses had a bachelors' degree of nursing. From the researchers' point of view, that the higher degree of nursing qualification always selected to work with the most vulnerable population like high-risk neonates. Also, the nurses who work in NICUs are better to be highly qualified and graduated from a college or university education.

As regards nurses' attainment of previous training courses, the majority of them (83.1\%) did not attend any training courses regarding nesting and swaddling for premature infants. This finding is consistent with Mohammed et al [28] who found that all nurses (100\%) did not attend any program or courses regarding developmentally supportive care of preterm neonates. In addition, the result of the current study is consistent with the findings of El-Sayed et al [33] who stated that, the most of nurses did not attend in-service training program before related to neonatal care at the NICU. The researchers justified these findings by lack of in-service education, continuous training and staff development in the study settings. In addition, data limited by developing countries suggest that nurses lack training regarding developmental care and its five domains including nesting and swaddling. Moreover, in the absence of formal training in nesting and swaddling, the knowledge and sensitivity of individual nurses towards those approaches become even more important factors.

Concerning the obstacles for performing nesting and swaddling for premature as reported by the nurses, the findings of this study showed that about two-thirds of nurses $(63.6 \%)$ stated that lack of knowledge about the benefits of nesting and swaddling for premature is an obstacle for providing it. Moreover, 35.1\% of them mentioned that shortage of staff and heavy workloads followed by $32.5 \%$ added disagreement between health team members are obstacles in providing nesting and swaddling for premature. While the minority (7.4\%) of them reported that nesting and swaddling measures are efforts without reward. These results are in harmony with Spilker et al [26] who found that the studied nurses reported several barriers to apply developmental positioning for infants in NICU.

The present study findings revealed that a small percentage of the nurses perform appropriate positioning and nesting before learning package as illustrated in Table 3. This could be explained by the lack of required hospital supplies and lack of knowledge regarding the performance of nesting and appropriate positioning. Meanwhile, the highest percentage of nurses performed appropriate positioning and nesting immediately and three months after learning package application. This finding may be due to nurses become more aware of different nesting methods and NICU equipped by multiple nests with different sizes. This finding is supported by Hunter et al [34] who reported that the nurses' training is an effective method to apply developmental positioning care at NICU by making a "nest" with soft boundaries, as well as a padded foot-roll for foot-bracing. Also, Zarem el al, [35] who concluded that, that nest is easy technique with little effort for the nurse but it provides effective developmentally supportive care positioning.

Nesting is a common developmental skill used by the nurses in NICU for premature infants. Because it maintains comfortable position, maintain normal vital signs, and facilitates extremities movement for promoting normal neuromuscular and skeletal joint function [25]. As regards making a nest supine or side lying supporting position of preterm neonates, the finding of the present study revealed that significant changes were noted in nurses' performance concerning making a nest supine or side lying supporting position as shown in Table 3. This finding is in harmony with Betts, et al, [36] who emphasized that the proper supportive side lying position by supporting the back and head in midline and bending the legs at the hips should be supported to prevent hyper-extension of the legs.

Developmental supported prone position must be well maintained because it improves sleep quality, preserves energy and facilitates weight gain [37]. The present study showed a statistical significant difference in nurse's performance regarding making a nest prone (Table 3) for keeping the spine straight, not curved to the right or left, and the back rounded. These findings could be interpreted by that nurses recognized the importance of proper prone position to support neuromuscular development, promote proper joint alignment and symmetry and promotes self-soothing and behavioral. In this context, Lucas, [38] mentioned that continuous applying the correct prone position, improve muscle tone development until 36 weeks and prevents postural deformities and helps motor development.

Regarding nurses' performance of swaddling for premature, the current study findings indicated that significant changes were noted in nurses' performance regarding swaddling after learning package application as shown in Table 4. This finding is in the line with Altimier et al [39] who emphasized that, provision of developmental care is important for neonate in NICU, 
because it used to decrease stress and pain through applying proper positioning and swaddling during caring for premature infants. Moreover, these measures will continue to move forward if considered from decision makers for professional education and practice.

Regarding total percent scores of knowledge and performance of nesting and swaddling for premature through phases of learning package, Table 5 indicated that the most of the nurses had poor total knowledge and performance' scores before application of learning package compared with immediate and 3 months after application of learning package with a very high statistical significant difference. The progress of knowledge's score may be attributed to wide varieties of educational methods used by the researchers $[3,40,41]$. This is in accordance with Edgar Dale's or the NTL's Pyramid of Learning as cited by many authors as the pyramid illustrated that individuals can retain $50.0 \%$ of what he demonstrates (see and hear), $30.0 \%$ of what he watches (video and image), $20.0 \%$ of what he hear, and $10.0 \%$ of what he read $[31,41,42,43]$. In the same line, the National Training Laboratories Institute has found that ones can retain 30.0\% of what he learned by demonstration and $75.0 \%$ by Practice by doing [44]. These findings are consistent with Chen, et al, [5] who reported that, improved nurses' cognition about premature infant nesting and positioning from $58.3 \%$ to $92.3 \%$ after application of the training program. Also the rate of correct technique uses increase from $63.3 \%$ to $91.4 \%$. Moreover, it is also in the same line with Spilker et al [26] who stated that, improving the developmental positioning proficiency of NICU nurses through applying a standardized infant positioning assessment tool and suitable strategies for education and training. Also, the results of the present study are in accordance with the findings of very recent study done by Masri et al [45] they confirmed that the mean knowledge assessment test score of nurses in the NICU who participated in this study improved significantly (p $<$.0001) after implementation of the learning package.

The present study findings revealed that the nurse majority had incompetent score regarding nesting and swaddling before the application of learning package, while this score of performance was highly improved immediately and three months after application of learning package with a highly statistical significant difference as shown in Table 5. The findings of present study are supported by Altimier et al [39] who reported that the Wee Care program improves staff satisfaction and engagement in care and promotes neonatal care and practices. It should be commonly applied in NICU to improve premature infants care. In addition, these findings could be interpreted by provision of nurses with supplies that facilitate their performance of nesting and swaddling as rolled sheets, nests and towel. Furthermore, this could be attributed to the impact of learning package application and keeping a booklet in the NICU which reminds nurses for appropriate positioning.

\section{Conclusions}

Based on the study hypotheses, the study concluded that there was an improvement in the nurses' knowledge and performance after implementing learning package related to nesting and swaddling for premature infants in the NICU.

\section{Recommendations}

Based on the previous findings, the following recommendations are suggested:

Neonatal nurses must be provided with the best evidences regarding the importance of applying nesting and swaddling technique for neonates in the NICUs as standard of developmentally supportive care.

Establish a written policy that regulates the use of nesting appropriate positioning through nesting and swaddling at NICU as a routine clinical practice.

Nursing curriculum should be equipped with the recent advances in neonatal care and students should also be trained to provide developmental care in an NICU setting.

Nursing educators and administrators at both unit and hospital levels should provide and recommend educational programs and supports in order to promote nurses' knowledge and attitudes, and consequently facilitate nurses’ practice regarding nesting and swaddling.

\section{References}

[1] Heron, M., Sutton, P., Xu, J., Ventura, S., Strobino, D. \& Guyer, B. (2010). Annual Summary of Vital Statistics: 2007. Pediatrics; 125: 4-15.

[2] Blencowe, H. et al. (2012). National, regional, and worldwide estimates of preterm birth rates in the year 2010 with time trends since 1990 for selected countries: a systematic analysis and implications. Lancet, 379: 2162-2172.

[3] Abd-Allah N., Nasr E., Hassan H. (2017). Impact of a Breast Feeding Educational Program for Mothers Having Pre-Term Infants in General Hospitals in Port Said. International Journal of Novel Research in Healthcare and Nursing, 4, (3): 215-225.

[4] World Health Organization (WHO). Preterm birth. (November 2015): Retrieved at: http://www.who.int/mediacentre/factsheets/fs363/e n/.

[5] Besser, L., Sabag-Shaviv, L., Yitshak-Sade, M., Mastrolia, S.A., Landau, D., Beer-Weisel, R. et al. (2018).Medically indicated late preterm delivery and its impact on perinatal morbidity and mortality: a retrospective population-based cohort study. J Matern Fetal Neonatal Med; 1:1-10.

[6] Lipner, H.S. \& Huron, R.F. (2018). Developmental and interprofessional care of the preterm infant: Neonatal intensive care unit through high-risk infant follow-up. Pediatr Clin North Am; 65(1):135-41.

[7] Haumont, D. (2014). NIDCAP and developmental care. Journal of Pediatric and Neonatal Individualized Medicine; 3(2):e030240.

[8] Network Lead Nurse. (2017). Wales Neonatal Network Guideline: Supportive Positioning Guideline. No. 5: 1-12.

[9] Poulose, R., Babu, M., ShardaRastogi, S. (2015). Effect of Nesting on Posture Discomfort and Physiological Parameters of Low Birth Weight Infants. IOSR Journal of Nursing and Health Science (IOSR-JNHS) e-ISSN: 2320-1959.p- ISSN: 2320-1940. 4, (1) (Jan.- Feb.), PP 46-50 www.iosrjournals.org.

[10] Mony, K., Selvam,V., Diwakar.,K.\& Raghavan,V. (2018).Effect of nesting on sleep pattern among preterm infants admitted in NICU. Biomedical Research; 29 (10): 1994-1997

[11] Waitzman, A. (2014). The importance of positioning the nearterm infant for sleep, play and development. Newborn and Infant Nursing Reviews 7: 76-81.

[12] Kihara H \& Nakamura T (2013. Nested and swaddled positioning support in the prone position facilitates sleep and heart rate 
stability in very low birth weight infants. Research and Reports in Neonatology 3: 11-14.

[13] Madlinger-Lewisa L, Reynoldsb L, Zarema C, Crapnella T, Inderc T, et al. (2014). The Effects of Alternative Positionin on Preterm Infants in the Neonatal Intensive Care Unit: A Randomized Clinical Trial. Res Dev Disabil 35: 490-497.

[14] Wambach, A. \& Hamvas, A. (2015). Respiratory distress syndrome in the neonate. In Martin RJ, Fanaroff AA, Walsh MC, eds. Fanaroff and Martin's Neonatal-Perinatal Medicine.10th ed. Philadelphia, PA: Elsevier Saunders; chap. 72.

[15] Abdeyazdan, Zahra, et al. (2016).Effects of nesting and swaddling on the sleep duration of premature infants hospitalized in neonatal intensive care units." Iranian journal of nursing and midwifery research 21. 5: 552.

[16] El-Nagger, N.S.M .\& Bayoumi,O.R.(2016). Effect of Applying Nesting Technique as a Developmental Care on Physiological Functioning and Neurobehavioral Organization of Premature Infants. Life Science Journal; 13(1S).

[17] Sathish, Y, Lewis,L.E., Noronha, J.N., George, A., Snayak,B., Pai, M.S., Bhat, R., Purkayastha, J. (2017). Clinical Outcomes of Snuggle up Position Using Positioning Aids for Preterm (27-32 Weeks) Infants. Iranian Journal of Neonatology. Mar: 8(1).

[18] Abusaad, F., E., Abd El Aziz,R.,A.,E.\& Nasef. A., A. (2017). The Effectiveness of Developmentally Supportive Positioning on Preterm Infants' Pain Response at Neonatal Intensive Care Units. American Journal of Nursing Science. 6, (1): pp. 63-71.

[19] Kim, Min-Jung, \& Tae-Im Kim. (2018). "Knowledge and Performance of Developmentally Supportive Positioning for Premature Infants among Neonatal Intensive Care Unit Nurses." Child Health Nursing Research 24 (2): 229-240.

[20] Maher, G.\& Elarousy, W. (2018). Effect of Nested and Swaddled Prone Positioning on Sleep and Physiological Parameters of Low Birth Weight Neonates. International Journal of Nursing and Health Science. 5(3), 48-55.

[21] Potter P.A., Perry A. G., Ross-Kerr J. C., Wood, M, J. (2006). Canadian Fundamentals of Nursing; 3rd Ed. Elsevier, Canada: 600-610.

[22] Nasr, E. \& Hassan, H. (2016). Association between quality of family planning services and client's satisfaction level in maternal and child health centers in Port Said city. Journal of Nursing Education and Practice; 6(1): 85-99.

[23] Hassan H., Gamel W., Abd El-Gawad, Sheha E., Sayed M., Arafa A. (2019). Menstrual disorders necessitating counseling among students in Beni-Suef University. Clinical Nursing Studies; 7(2): 29-36.

[24] Farg D. and Hassan H. (2019). Study Hyperemesis Graviderum Requiring Hospital Admission during Pregnancy: Effect of Nursing Implication on Its Progress. American Journal of Nursing Research; 7(3): 328-341.

[25] Chen, C.M, Lin, K.H, Su, H.Y, Lin, M.H.\& Hsu, C.L.(2014). Improving the provision of nesting and positioning for premature infants by nurses in neonatal intensive care units. Hu Li Za Zhi. Apr; 61(2 Suppl):S41-9.

[26] Spilker, A., Hill, C, Rosenblum, R. (2016).The effectiveness of a standardized positioning tool and bedside education on the developmental positioning proficiency of NICU nurses. Intensive Crit Care Nurs. Aug; 35:10-5.

[27] Godarzi, Z., Rahimi, O., Khalessi, N., Soleimani, F.,, Mohammadi, N. \& Shamshiri, A. (2015). The rate of developmental care delivery in neonatal intensive care unit. Iran J Crit Care Nurs.; 8(2): 117-124.

[28] Mohammed, R., Khamis,G.M. \& Sabry,Y.Y. (2018).Effect of Preterm Neonates' Developmental Supportive Care Program on Nurses' Performance. IOSR Journal of Nursing and Health Science (IOSR-JNHS) e- ISSN: 2320-1959.p- ISSN: 2320-1940. 7, (4) (Jul.-Aug.), PP 33-45.
[29] Abd El- Aziz,D.E., Abd El Aziz,M.A., Adly,R.M. \& El Sallab,S.M. (2018). Improving Nurses' Performance towards NonPharmacological Pain Management among Neonates In Neonatal Intensive Care Unit. IOSR Journal of Nursing and Health Science (IOSR-JNHS) e- ISSN: 2320-1959.p- ISSN: 2320-1940. 7, (4) (Jul.-Aug.), PP 33-45.

[30] Costa, T., Rossato, L., Bueno, M., Secco, I., Sposito, N., Harrison, D., \& Freitas, J., (2017). Nurses' knowledge and practices regarding pain management in newborns. Revista da Escola de Enfermagem da USP, 51.

[31] Hassan H, \&Nasr E. (2017). Improving nurses' knowledge and skills regarding tocolytics for inhibiting preterm labor. Clinical Nursing Studies; 5(1): 1-12.

[32] Mehrnoush, N., Ashktorab, T., Heidarzadeh, M., \& Momenzadeh, S. (2017). Knowledge and attitude of personnel, key factors in implementation of neonatal pain management in NICU: A Qualitative Study. Journal of Clinical \& Diagnostic Research, 11(11). Retrieved from, http://www. .jcdr.net.

[33] El-Sayed, S., Sabry, Y, Sharkawy, H, El-Sayed E. and Ali, T. (2013). Establishing basic standards of nursing care protocol at neonatal intensive care unit. Nature and Science 11(4). Retrieved from, http://www.sciencepub.net/nature.

[34] Hunter, J., Lee, A.\& Altimier, L. (2015).Neonatal intensive care un occupational therapy for children and adolescents. St. Louis: Elsevier, St; pp. 595-635.

[35] Zarem, C., Crapnell, T., Tiltges, L., Madlinger, L., Reynolds, L., Lukas, K. et al. (2013).Neonatal nurses' and therapists' perceptions of positioning for preterm infants in the neonatal intensive care unit. Neonatal Netw; 32(2):110-6.

[36] Betts, K., Watson, G., Roy, R. (2015). Joint Trust guideline for the management of developmental care of pre-term neonates. Norfolk, UK: James Paget University Hospitals, Norfolk and Norwich University Hospitals; Pp.2-12.

[37] Gouna, G., Rakza, T., Kuissi, E., Pennaforte, T., Mur, S. \& Storme, L. (2013).Positioning effects on lung function and breathing pattern in premature newborns. J Pediatr 2013; 162(6):1133-7.

[38] Lucas, N. (2015). Developmental care in the neonatal unit. Sri Lanka Child Health J; 44(1): 45-52.

[39] Altimier, L., Kenner, C., Damus, K. (2015).The wee care neuroprotective NICU program (Wee Care): The effect of a comprehensive developmental care training program on seven neuroprotective core measures for family-centered developmental care of premature neonates. Newborn Infant Nurs Rev; 15(1): 6-16.

[40] Hassan H., Mohamady Sh., \& Abd El-Gawad N. (2017). Protocol for improving nursing performance towards placental examination at labor units. Clinical Nursing Studies, 5(2): 1-11.

[41] Faheim S., Hassan H. , Gamel W. (2019). Topical Application of Human Milk versus Alcohol and Povidine-Iodine on Clinical Outcomes of Umbilical Cord in Healthy Newborn: Impact of an Educational Program of Mothers' Knowledge and Practice Regarding Umbilical Cord Care. International Journal of Studies in Nursing; 4(2): 35-51.

[42] Hassan H. (2018). Effectiveness of a structured teaching program on anxiety and perception regarding toxoplasmosis among seropositive pregnant women in Northern Upper Egypt. Clinical Nursing Studies, 6(1): 1-19.

[43] Hassanine Sh., Hassan H., Alkotb Z. (2017). Effect of Preventive Program on Progression of Osteoporosis among Female Patients over 40 years at El-Fayoum City. American Research Journal of Nursing, 3(1): 1-15.

[44] Kumar, A. (2007). Personal, Academic and Career Development in Higher Education-SOA Ring to Success London and New York, pp. 1-33. Routledge Taylor \& Francis Group.

[45] Masri, S., Ibrahim, P., Badin, D., Khalil, S.\& Charafeddine, L. (2018).Structured Educational Intervention Leads to Better Infant Positioning in the NICU. Neonatal Netw. Mar 1; 37(2):70-77. 